\title{
Culture, Knowledge And Experience-Based Interpretation Of Political Metaphors
}

\author{
Maia Chkheidze ${ }^{1}, \operatorname{Revaz}_{\text {Tabatadze }}{ }^{2}$ \\ ${ }^{1}$ The University of Georgia, Georgia, ${ }^{2}$ The University of Georgia, Georgia
}

\begin{abstract}
.
The paper focuses on the problem of teaching and learning political metaphors and focuses on the mentioned problem from a cross-cultural perspective. The results of the survey carried out among Georgian English learner students provide valuable insights into how Georgian English learner students perceive the reality and conceptualize political processes.

The way we perceive the reality is differently realized in different languages, in other words, different languages diversely segment the reality. World view is a culture, knowledge and experience-based interpretation resulting from the subjective perception and conceptualization of the reality.
\end{abstract}

The findings of the survey carried out among Georgian English learner students suggest that learners usually give adequate interpretation to the elements with the high degree of usage and significant cross-cultural correspondence.

The method of application of the expectancy violation effect in teaching and learning political metaphors is emerging in this paper as an effective tool that is capable of providing serious assistance to both teachers and students.

Keywords: Political metaphors, subjective perception, conceptualization, expectancy violation.

\section{Introduction}

We settle in the real world by naming objects, events and determining their place in the real world. Each language creates its own world view through which the language bearer organizes the content of the expression.

Language is a means of molding human knowledge on the universe. While reflecting the reality, a human being translates the perception outcomes into words. The sum total of the knowledge, accumulated through the linguistic forms is the lingual representation of the world. 


\section{BEHAVIORAL \& SOCIAL SCIENCES}

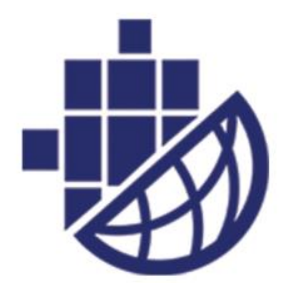

\section{3 - 25 October, 2020}

Amsterdam,Netherlands

A lot of research has been made on the specifics of metaphoric language and use. Lakoff and Johnson's publication "Metaphors We live by" (Lakoff \& Johnson, 1980) offers a fresh view of metaphors in language today. According to Lakoff and Johnson, there is a close link between language, metaphors and thought. Lakoff and Johnson argue that people think in metaphors (Lakoff \& Johnson, 1980).

Metaphors add great expressive and emotive power to idiomatic expressions. Since metaphors comprise both emotional and evaluative connotations, they mold people's values, beliefs and attitudes.

Following the cognitive semantic approach originated by Lakoff and Johnson, CharterisBlack (Black, 2005) asserts that metaphor uses language to activate unconscious emotional associations and influences our values, beliefs and attitudes by transferring positive or negative associations into the metaphor.

The cognitive semantic approach offers linguists the opportunity to study both the universal and the culturally marked (unique) characters of conceptual metaphors. Though conceptual metaphors are based on our basic human experience, we all exist in different cultural spaces. Influencing our perception of the universe, our cultural backgrounds condition the specifics of our world view and our use of metaphors.

\section{Methodology}

The analysed data were collected applying the method of expectancy violation in teaching political metaphors to the Georgian English learners with upper-intermediate level of language proficiency in general English.

Expectancy violation effect occurs when the essence of the expression turns out to be completely unexpected and distinct from the predicted one. Expectations and anticipations as well as violation of expectations and anticipations arise on the basis of two psycholinguistic phenomena - predictability and unpredictability.

We interpret violation of expectancy as the variability of the definition of the figurative element, in particular, the possibility of developing several definitions of the figurative element.

Psycholinguistic experiments focused on the understanding the essence of political metaphors are associated with the mechanism of guessing. The mentioned mechanism implies the construction of hypothesis. Specifics of the constructed hypothesis are determined by the level (high/low) of language competence, degree (high/low) of frequency of the usage of figurative elements, as well as by the effect of associative precedence.

Sharing the idea that "To err is human", we think that the more certain learners are of their wrong answer, the better they learn the right one after being corrected. "Error shock" is likely 


\section{BEHAVIORAL \& SOCIAL SCIENCES}

to turn into a positive stimulus and an enhancer of learners' language competence and the enjoyment of learning figurative repertoire of political communication.

\section{Body of paper}

Figurative elements really give political communication an "aesthetic character". Learners acknowledge this fact but they try to verbalize their thoughts, ideas and emotions without the help of figurative elements. The problem is that, in the beginning learners can't see any need for "thinking outside the box", in other words, they can't see any need for combining elements having little or no logical connection. The only way to direct learners' attention to the metaphoric world of political communication is to let them choose between long and laconic constructions.

The results of the experimental study revealed the psychological peculiarities of thinking in the process of second language acquisition.

The analysis of the results derived from the experiment revealed the following fact: learners usually give the adequate interpretation to the elements with the high degree of usage and significant cross-cultural correspondence. The list of such elements looks the following way: Demagogue (A political leader who seeks support by appealing to popular desires and prejudices rather than by using rational argument; Electorate (All the people in a country or area who are entitled to vote in an election; Exit poll (A poll of people leaving a polling place, asking how they voted); Front Runner (The political candidate that is in a leading position in a race or other competition); Primaries (A preliminary election to appoint delegates to a party conference or to select the candidates for a principal, especially presidential, election); Voter bloc (A group of voters that are strongly motivated by a specific common concern or group of concerns to the point that such specific concerns tend to dominate their voting patterns, causing them to vote together in elections); Rhetoric (Language designed to have a persuasive or impressive effect on its audience, but often regarded as lacking in sincerity or meaningful content); Bread and circuses (Satisfaction of shallow or immediate desires of the populace at the expense of good policy; also, the erosion of civic duty and the public life in a populace); Witch-hunt (A hysterical pursuit of political enemies); Politics is sports (game); Politics is a play (theater); Politics is a journey; Politics is war.

The comparison and contrast of English and Georgian figurative models manifest the following common source concepts: Sport, Play, Business, Money, Natural Phenomena. These models reveal a certain similarity of metaphorical comprehension of political issues in English and Georgian political communication. However, there are some models marked by nationally specific features confirming the uniqueness of the world view of each culture, linguistic consciousness and value orientations.

The Analysis of the results of the research experiment carried out at the University of Georgia revealed that the expectancy violation effect was extremely interesting when non-native 


\section{BEHAVIORAL \& SOCIAL SCIENCES}

speakers with no knowledge of political communication were asked to define political metaphors.

Here is the example of misinterpretation of the element "parachute candidate" (adequate interpretation: a candidate who runs for election in an area which he or she is not a native resident or has no ties). According to some learners, "parachute candidate" is a candidate who is forced to leave the political party. The misinterpretation has been influenced by the association with the element "golden parachute" (adequate interpretation: a large payment made to someone who has an important job with a company when that person is forced to leave their job).

Misinterpretation of the element "fishing expedition" (adequate interpretation: an investigation carried out without any clearly defined plan or purpose, in the hope of discovering useful negative information about someone) resulted from the association with the element "fishing in the air" (adequate interpretation: making vain efforts, wasting time).

According to some learners, "to vote with one's feet" (adequate interpretation: to leave a country right after voting) means "to make a free choice of candidates" (adequate interpretation: to be strong and independent; to not need the guidance, or resources of another person). The interpretation has been influenced by the association with the element "to stand on one's own two feet".

Misinterpretation of the element "turkeys voting for Christmas" (adequate interpretation: acting against one's own interests with no conceivable gain) has been marked by the "stupid turkey" stereotype. Some learners remember the stories of how turkeys are so stupid that they sometimes look up while it's raining and keep staring skyward until they drown.

Having been influenced by the mentioned association, some learners developed the following definition: "Turkeys voting for Christmas" means "Stupid people vote for something that needs no voting."

According to some learners, "lame duck" (adequate interpretation: a politician or a government that doesn't have much real power because their period in office will end soon and their successor has already been elected) is a politician who used to be bad, but after some time turned out to be good. The misinterpretation resulted from the association with the element "ugly duckling" (adequate interpretation: a person who turns out to be beautiful or talented against all expectations).

Misinterpretation of the element "political hot potato" (adequate interpretation: something potentially dangerous or embarrassing) has been influenced by the association with the element "having a potato in the mouth" (adequate interpretation: trying to form a sentence and make a point, but the sentence is incomprehensible. It is a term for a defect of resonance in which the speech has muffled quality). 


\section{BEHAVIORAL \& SOCIAL SCIENCES}

Having been influenced by the mentioned association, some learners developed the following definition: "political hot potato" is a politician whose speech is incomprehensible.

According to some learners, "dreamers" (adequate interpretation: the term for young children of undocumented and illegal immigrants brought to the country as children who would be eligible for rights to stay, work or obtain legal residency and citizenship) are the members and supporters of the governing party of Georgia - Georgian Dream - Democratic Georgia. Most informants think that the element "dreamers" has a negative connotation resulted from the association with the element "Don't waste your time on just doing nothing but dreaming".

The research experiment reveals that most informants know the meaning of the element "Black Lives Matter" (A social activism loosely-formed organization that works to advance causes of concern to the black American community, mainly around social justice, equality and police-involved shootings and killings of unarmed African American and black people). Only some informants have misinterpreted the element. The misinterpretation resulted from the association with the element "be in the black" (adequate interpretation: refers to the person who is in trouble or need).

Every culture has its own associative field of "color". But different cultures attach different connotations to the field constituents. In Georgian, when we say "in the black", we mean that someone is in a terrible situation. In Georgian "black" is associated with fear, mystery, death, evil, grief, poverty and aggression.

Learners linked the element "black" with "save for a rainy day" (adequate interpretation: to reserve something, especially money, for use in a time or period of unforeseen difficulty, trouble, or need), because the Georgian counterpart of the element "save for a rainy day" is to "save for a black day".

So, Georgian learners developed the following definition: "Poor people's lives matter".

The results of the experimental research proved that subjective perception of a particular political metaphor or idiom is determined by linguistic and extra linguistic (culture, knowledge, experience etc.) factors.

\section{Conclusion}

The results of the experimental research have led us to some discoveries about the close links between the conceptual knowledge, word meaning, perception and to practical research on the specificity of communication involving figurative language in various contexts, including teaching English.

Any act of interpretation implies the relation of information with knowledge schemes. The existence of an internal (mental) context, being the basis for generating the expression and its perception, is obvious. 
$7^{\text {th }}$ International Conference on Research in

\section{BEHAVIORAL \& SOCIAL SCIENCES}

23 - 25 October, $2020 \quad$ Amsterdam,Netherlands

Internal context is the product of an individual's activities covering the perceptual and cognitive, verbal and non-verbal, continuous and discrete aspects of an individual's life. Internal context, along with the knowledge schemes, is determined by emotions, knowledge repertoire, and external context.

\section{References}

Charteris-Black, J. (2005). Politicians and Rhetoric. The Persuasive Power of Metaphor. Basingstoke: Palgrave McMillan.

Lakoff, G., Johnson, M. (1980). Metaphors We Live by. Chicago: University of Chicago Press. 